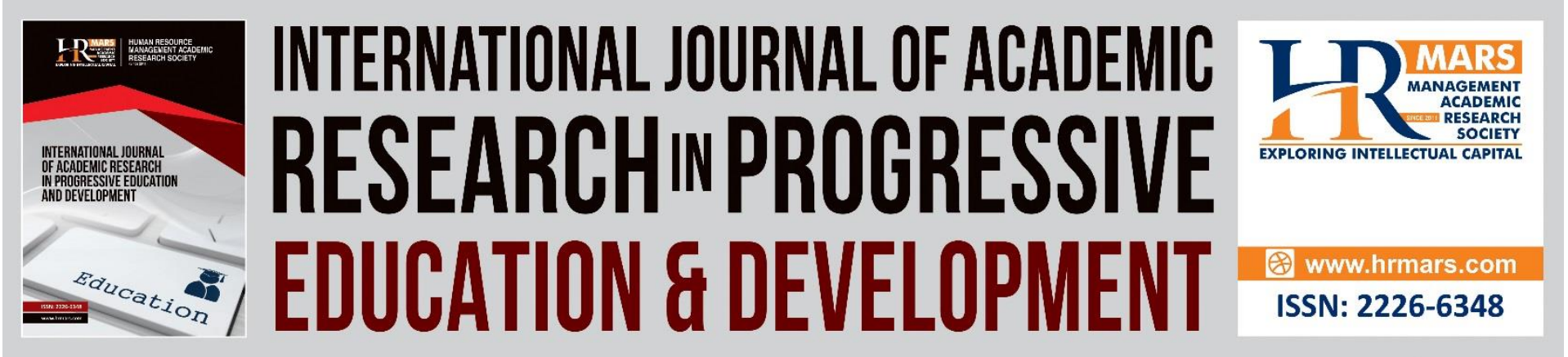

\title{
Merit and Challenges of Online Teaching in India and Malaysia
}

Avdhesh Jha and Logaiswari Indiran

To Link this Article: http://dx.doi.org/10.6007/IJARPED/v10-i2/10491

DOI:10.6007/IJARPED/v10-i2/10491

Received: 19 May 2021, Revised: 23 June 2021, Accepted: 17 July 2021

Published Online: 28 July 2021

In-Text Citation: (Jha \& Indiran, 2021)

To Cite this Article: Jha, A., \& Indiran, L. (2021). Merit and Challenges of Online Teaching in India and Malaysia. International Journal of Academic Research in Progressive Education and Development, 10(2), 1110-1123.

Copyright: (C) 2021 The Author(s)

Published by Human Resource Management Academic Research Society (www.hrmars.com)

This article is published under the Creative Commons Attribution (CC BY 4.0) license. Anyone may reproduce, distribute, translate and create derivative works of this article (for both commercial and non-commercial purposes), subject to full attribution to the original publication and authors. The full terms of this license may be seen

at: http://creativecommons.org/licences/by/4.0/legalcode

Vol. 10(2) 2021, Pg. 1110 - 1123

http://hrmars.com/index.php/pages/detail/IJARPED

JOURNAL HOMEPAGE

Full Terms \& Conditions of access and use can be found at http://hrmars.com/index.php/pages/detail/publication-ethics 


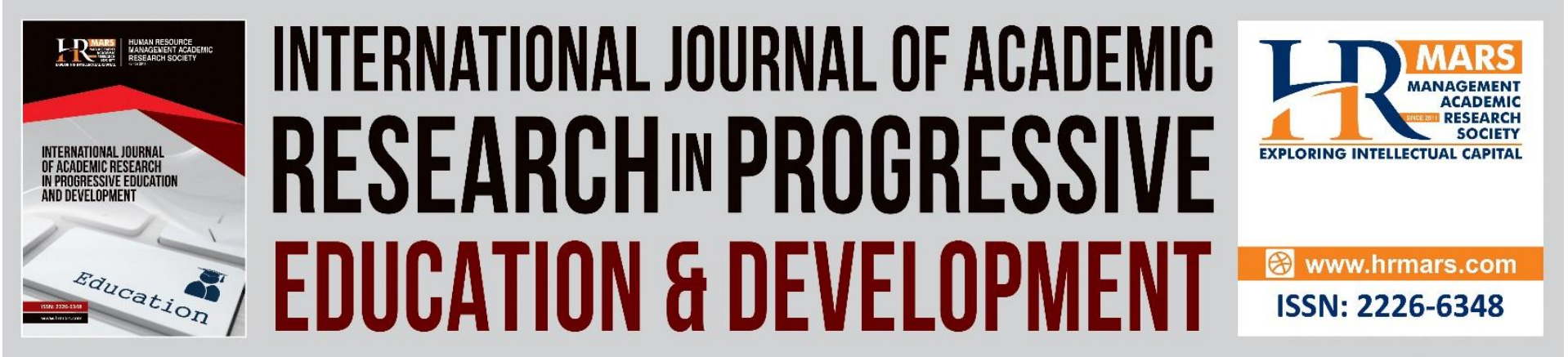

\title{
Merit and Challenges of Online Teaching in India and Malaysia
}

\author{
Avdhesh $\mathrm{Jha}^{1}$ and Logaiswari Indiran ${ }^{2}$ \\ ${ }^{1}$ Dean, Faculty of Education, Waymade College of Education, CVM University, India, ${ }^{2}$ Senior \\ Lecturer, Azman Hashim International Business School, Universiti Teknologi Malaysia, \\ Malaysia \\ Email: jhaavdhesh@yahoo.co.in
}

\begin{abstract}
An attempt has been made to articulate the ideas of online teaching in a comprehensive manner. The study unifies the merits, and challenges of the online teaching - a new, or as a different alternative and even as a supplement of traditional teaching which had to be forcefully promoted by the government in several developing countries due to COVID 19 pandemic and the same was adopted forcefully in most cases by the teachers in their teaching practices which aroused several questions for students, teachers, and parents. The objective of the study thus comprised to know the perception of the students, teachers, and parents towards the merits, and challenges of online teaching in India, and Malaysia. Interviews were conducted on the students, teachers, and parents in both the countries. The findings indicate that major merits of online teaching include flexibility in learning, economical with respect to time, money, and energy, access to knowledge, and fostering communication. The major challenges are issues and threat of technology, gender issues, problems associated with rural people and communications. The study concludes the similarity and differences of the merits and challenges of online teaching among two countries and provides a new insight to the future academicians and practitioners.
\end{abstract}

Keywords: Merit, Challenges, Online Teaching, India, Malaysia

\section{Introduction}

Amidst the hopes and high aspirations, twenty-first century is a bulk of challenges and changes especially with respect to health, hygiene, education, social change, technological development, and, economy. With pandemic when everything seemed to be stand still, it was the human nature that insisted him to move ahead and so it was that even in pandemic, education never came to a standstill. UNO (2020) reported that the COVID 19 pandemic has created the largest disruption of education systems in history, affecting nearly 1.6 billion learners in more than 190 countries and all continents. It was only because the human found the alternate options in education and thus initiated the era of online education. While there was a mix of ideas about the implementation, acceptance, and success of online education; the situation and time forced each one to accept it whether whole heartedly or with a heavy 
heart. Acceptance led to effective continuation of the education and the loss of academic sessions was lessened. Research results by Paudel (2021) show that large number of participants found online learning beneficial even if it was their first experience having fully online courses, teaching, and learning situation created due to pandemic COVID 19.

In online teaching, teaching of lessons or syllabus is specifically done with help of internet connectivity and technology aided devices to turn the teaching learning process effective. It is thus the process of educating the prospects via the internet. Various ways of teaching include webinars, conference calls, group video call, and one to one call. There are various applications available online which makes the ease in online teaching such as Zoom, Skype, Google Meet, Google Classroom, Big Blue Button and others. With help of these applications, it becomes feasible, convenient, reliable, and easy mode of teaching on the part of teacher. Not restricted to the ease and earning, online teaching broadens the view of knowledge as we get in contact with various people of different age group, different geographical areas, and different interest areas.

However, at the same time online teaching get criticized due to many challenges such as the network issues, lack of technology aid gadgets, lack of technical skills to use it and various other problems and others issues especially in rural areas. Since every event has two sides, so has the online education which is adorned with the merits and challenges. Therefore, the objective of the study is to explore the merits and challenges of online teaching from the perspective of students, teachers, and parents in India and Malaysia, utilizing the Cognitive Flexibility of Theory.

\section{Merit and Challenges of Online}

As of the 7th of July, 2021, more than 184.97 million cases of Coronavirus disease 2019 (COVID 19) had been reported in more than 188 countries and territories, resulting in more than 4.0 million deaths, according to the World Health Organization. The COVID 19 outbreak has had a negative impact on educational system around the world, resulting in the near-total closure of schools, universities, and colleges in several countries (Huang, 2020). Many educational institutions, ranging from the most basic to the most elite, in both India and Malaysia have begun their semesters entirely online. Educators have been putting pressure to overcome the numerous challenges they have faced and to ensure that teaching and learning continue to take place as smoothly as possible during this unprecedented crisis. However, it cannot be denied that online education has a variety of benefits for a most of the stakeholders.

\section{Merit}

As Kim and Bonk (2006) point out, technology has played a significant role in the development and expansion of online education, and it continues to do so. In response to the pandemic, educators are increasingly relying on technological tools for teaching and learning that have a positive impact on the educational process. Online teaching and learning have been a topic of discussion for quite some time. The use of technologies facilitates the management of large numbers of students from various parts of the world, and as a result, at the institutional level, learning through the use of technologies may be considered a cost-effective teaching method (Botham \& Mason, 2007). Some of the most significant advantages of online teaching and learning are interaction and student engagement, access to the most recent information, 
content sharing, and mass communication (Mathew \& Ebelelloanya, 2016). Technologies have the potential to transform higher education in a variety of ways: Fundamental shifts in instructional methods, and content, and assessment are made possible by digital technology (West, 2012). As a result, the advantages of utilising technology for online teaching and learning have been extensively documented in the literature.

\section{Challenges}

The transition from traditional to online learning comes with its own set of difficulties to overcome. As a result, students, teachers, and parents are all confronted with a variety of difficulties when participating in online learning during the COVID-19 pandemic that is sweeping the world (Li \& Lalani, 2020). Even prior to the outbreak of the pandemic, the most significant online teaching and learning challenges that African students face are access to technology, and affordability (Mathew and Ebelelloanya, 2016). While the Indonesian education system is uneven, as is the case in different sectors of society, this is especially true in light of the upcoming pandemic COVID-19. Some schools receive funding, whereas other schools do not receive any funding. In Indonesia, challenges to online teaching include a complex educational context, difficult economic conditions, anxiety during online learning, an untrustworthy government, and the possibility of user data security breaches (Simamora, 2020). While in India, the main challenges are primarily related to broadband connectivity issues, which are particularly problematic in rural areas and make it difficult for students to take advantage of online learning initiatives (Muthuprasad et al., 2021). In Malaysia, the level of preparedness is still low, whether among students or among educators (Yusuf \& Jihan, 2020).

Looking at the merits and challenges of online learning that have arisen around the world, this study investigated the online merits and challenges of students, teachers, and parents in India and Malaysia. How far can online learning take the place of traditional classroom instruction, or can it serve as a partial supplement to it?

\section{Theoretical Framework}

The COVID 19 pandemic has brought to the forefront in exaggerated fashion a world that we have been increasingly confronted with in recent decades, a world marked by increasing illstructuredness, unpredictability, complexity, and novelty. Th key goal of Cognitive Flexibility Theory is to prepare students to deal with such a world necessitates the inclusion of instructional teaching and learning features that promote and support the ability to manage real-world complexity and to deal adaptively with novel, ill-defined problems (Spiro et al., 1988, 1992, 2017, 2019; Spiro and Jehng, 1990). Possessing the high-order ability enables an individual to adapt cognitive processing strategies in response to novel, unexpected, and changing circumstances. Therefore, the cognitive flexibility theory was applied in this study, which is based on the theoretical work of Spiro et al. (1987), who describe "instructional design guidelines for advanced learning in ill-structured domains" (Cheng \& Koszalka, 2016: 2).

\section{Research Questions}

The purpose of this study is to identify the most highly referenced merit and challenges of online learning as perceived by students, teachers, and parents in India and Malaysia, 
respectively. Specific questions addressed by the study include the following in relation to the experience of India and Malaysia with online teaching during the first year of the transition from face-to-face teaching to online teaching in the context of the COVID-19 pandemic:

RQ1: What are the merits of online teaching?

RQ2: What are the challenges of online teaching?

\section{Research Methodology}

Students, teachers, and parents from India and Malaysia participated in a qualitative study using semi-structured interviews to examine the merits and challenges of online teaching during the first year of the COVID-19 programme in India and Malaysia. The respondents who took part in the study were ten students, ten teachers, and ten parents who came from different parts of India and Malaysia. The experts or teachers are individuals who are knowledgeable, but they are a mixture of chosen and unpreferred online teaching educators, while some are technologically savvy, form various educational institutions in India and Malaysia. When it comes to students, the respondents are who do not appreciate online learning but do enjoy gaming and social media. Some are from those who consider academics to be a vital element with different levels of education. Parents, either literate or illiterate with online teaching are the respondents in both countries.

\section{Result and Discussion}

\section{Merits of Online teaching as a preferrable mode}

During the pandemic when the direct contact was considered risky, online education proved to be a boon. Nevertheless, online teaching had the potential to create educational opportunities for individuals who may have faced unsurpassable barriers prior to the expansion of online educational programs. The interviews with the students, teachers, and parents presented the following reasons that represented why online teaching turned to be a preferred mode as compared to the traditional classroom teaching.

Learning anywhere at any time: Online education provides the flexibility to study at your own pace and from any location. Even while on the road, one can continue to educate oneself. It satisfies the notion of education being available at any time and from any location, at least for those who can afford it. Information is exchanged through various means such as chats, messages, and so on. For both teachers and students, online interaction can be a valuable learning experience (Paudel, 2021). In this regard, students and teachers in India believe that they have the freedom to learn at any time and from any location. Like Malaysia, there is a high degree of adaptability since mobile learning is the most common delivery system for online education, which can be delivered via desktops, laptops, tablets, and smartphones, among other devices.

Savings on transport and time: Huge amount of money and time is saved on transport since education is at our doorstep, there is no need of transport to undertake education. Time, money, and energy are all saved because of this. There is accessibility in terms of availability of time and location. Travel expenses can be kept to a bare minimum. Physical presence is not required, allowing for greater time, money, and energy savings, as well as greater flexibility in terms of time and location (Paudel, 20211; Arkorful \& Abaidoo, 2015). In this particular instance, both counties are entitled to the same benefit. The parents have stated 
that they felt safe because there was less risk to the children, and that they were able to ensure economic benefits. While the teachers from India and Malaysia shared the same views on the economic benefits, they were more concerned with the time saved by not having to travel, which they said could be used for material preparation or other activities depending on their priorities.

More independence: It leads the teacher to plan the activities in their best and convenient time, classes can be taken from all places, but the internet connectivity needs to be good, additional commitments can also be undertaken and new ideas can be learned at home. Students and teachers in India felt that online education makes them flexible about what, when and how some tasks are to be performed. This allows you to be more creative. This implies to Malaysia as well.

Less emphasis on physical infrastructure: Additionally, online teaching helped to reduce the reliance on infrastructure and instructional facilities. Many unwanted classroom and school issues are reduced. This condition will overcome the school that has poor infrastructure, including water and electricity facilities, as well as sanitation facilities, for India, particularly for education institutions in rural areas, and will help the school to succeed. Even some of the schools in cities are experiencing the same infrastructure problems. Malaysia, on the other hand, hardly faces problems with water and electricity, but the other infrastructure could be overcome.

Expert availability: Expert can deliver lecture to many learners, at various locations. Due to online classes, teachers can expand their knowledge through online resources. Experts can be pooled from anywhere, which holds for both India and Malaysia.

Affordable: Affordability applies to people from the middle and lower classes because data is available at a reasonable cost for them. Recurring revenue expenses such as stationery and gasoline are also delimited, allowing for cost savings to be realised. It was reported by a stakeholder in India that getting internet data is affordable because it is less expensive than paying for school fees. During the first wave of the pandemic, the Malaysian government provided all students with a free internet data plan, courtesy of the government. As a result, both countries are perceiving similarly when it comes to affordability.

Comfort of home with fresh minds: If the home environment is peaceful and learning is conducive, then studying online at home can make the learning more enjoyable and valuable. There is less distraction as students study alone (Paudel, 2021). Sometimes the student may distract the other student while the teacher is teaching in class. But this aspect may not happen if the home environment is totally conducive. Modes of teaching include real time as well as learn at your time. These are the reported statement from all the stakeholders include students, teachers and parents from India. In another hand, Malaysian teachers and students mentioned that the fresh mind while studying or teaching from home are only temporary.

Interactive learning using audio-visual tools: This might be the biggest boon of online teaching. There is plethora of audio video tools which can be used to make the learning experience interactive and enjoyable. This can be accomplished through the variety of tools. 
It is simple and convenient for all techno savvy students and teachers to utilise. It is possible to record the sessions and use them again and again for the stakeholders. This holds true for both countries.

Certificate courses: Many certificate courses for skill development are available online that are not included in the traditional classroom curriculum. Many of them do not have any immediate deadlines to complete the course, and students can complete these courses at their own pace, which is particularly true in India. While in Malaysia, such certificate courses are hardly available.

Administration: Unlike classroom teaching, a teacher doesn't have to keep track of multiple students. This decreases the administrative burden while improving the concentration and performance of a teacher which is helpful on the part of teacher to improve concentration and performance in both countries.

Distance teaching-learning: Online teaching can be best used in distance teaching-learning. Student from remote location can also study (Sun \& Chen 2016). Both countries stakeholder reported the same for the online distance teaching-learning, where it helps any and many of the students and teachers.

Increased students learning: Compared to offline mode of learning in higher education, online mode seems to be friendlier with the students in terms of attendance, participation in activities, creativity, discussions which intends to be favourable for the better performance of the students, especially in India. However, in Malaysia, not many students and teachers agreed to this point. They are still more incline to the traditional mode of learning.

Less intimidating: With 74 percent of people suffering from speech anxiety, according to the National Institute of Mental Health, online education tends to foster better class participation. Those having fear, shyness, and anxiety of speaking in front of everyone in classroom tends to do better. The online teaching turns helpful to make them feel free and have open platform to speak and share their thoughts, views, and ideas. This implies to both countries.

Basically, there were plenty of reasons to let online education be a preferred mode of education but only if one has a good internet connection, remain techno savvy and has techno gadgets.

\section{What are the Challenges of Online Teaching?}

A survey done in 2018 indicates that $30 \%$ of our population lags on basic literacy and thrice that for digital literacy. Various negative emotions have been mostly seen in online learning research paper such as anger, boredom, frustration, confusion and isolation. The interviews with the students, teachers, and parents presented the following challenges faced during online teaching in India and Malaysia.

Lack of skills: Teachers are not acquainted with skills related to online techniques, effective use of application, familiarity with new improved version of application, and various techno 
equipment's which hinders the education practices. Teaching role remains ineffective. This implies to both countries as well, especially for developing and underdeveloped countries, where the technology advancement is yet to reach the potential prospect. It become difficult for them to use when it comes all of the sudden, especially for the people of middle age and above, which is observe among the teachers of India. While in Malaysia, same cases happen, especially for those who are senior lecturers or teachers. They are good in the content, but they are not technology savvy. This posits challenges on online teaching.

Over Rely on Online Teaching Aids: Teachers and students turned to rely more on technology, audio and video, without much effectiveness and online material which is available and may not be reliable is used as supplementary reading material. The teachers ignore the reliability and validity of the content. Preparing or writing a good teaching material is not everyone's cup of tea, especially those who are not good in language. This prompt the educator to just rely too much on the internet resources, reported in both countries. In addition, the teachers are only focusing on the content, and ignoring the other important soft skills elements.

Emotional Touch: Emotions could be hardly felt and no direct communication because of which difficult to judge the changes and development. The lack of inquiry on the emotions of learning is even more visible in online learning contexts. Electronic learning has been depicted as less emotional and more impersonal. A teacher in India college mentioned that he is a famous and successful teacher during traditional class. However, now he felt emotional touch is seriously missing in online teaching. While Malaysian teachers felt that that the communication is just one way, where the teachers remain just talking to the wall. This is one of the main challenges in online teaching that must be overcome seriously.

Lack of Interaction: There is a lack of interaction between the students and the teachers, difficulty in providing feedback to students, and difficulty in teaching. Effective eye to eye contacts not possible, only one way communication takes place. Teachers who have taught online courses reported that it took much more time teaching online classes than face-toface mode (Keengwe \& Kidd, 2010). This implies to both countries.

Threat to Girl Child: According to a Harvard study, 71\% of men in India own mobile phones. Only $38 \%$ of women, however, have access to the device. The problems with these transitions are only starting to show in Mallapuram, Kerala a 14 year old Dalit girl died by suicide due to the inability to accessing online classes in June, 2020. While, in Malaysia, gender equality is practiced highly, where both male and female child have the same threat in all the sectors and industry at any level.

Threat to Female Faculty: Online classes is a horror for many teachers. If online classes are boring for students, they are absolutely crushing for teachers who face abuse and humiliation from the students. For example, a faculty of political science teacher was taking an extra lecture as she wanted to finish the topic and there was strange request from unknown source. After admitting him to the class and as she started teaching, she was abused. In Malaysia, similar situation has not been reported yet. 
DEVELOPMENT

Vol. 10, No. 2, 2021, E-ISSN: 2226-6348 ㄷ 2021 HRMARS

Technology Threats: Children are smart to use technology. Their inquisitiveness and curiosity help them know the minutest detail. Because of the lack of maturity and with no control on technology and internet, the children are prone to threat of abuse of technology. Further, there is no way to trace or control the children activity on internet and technology. This implies to both countries.

Technology Issues: Technology issues are experienced, and students cannot focus on studies. Again, teaching and learning process (TLP) is dependent on internet and power resources which is beyond our control. Nevertheless, hardware is not up to the mark, and lack of awareness of common man about using technology is a serious and severe issue. Not with standing, every student hardly has sufficient internet facility and smart phone in both countries, especially in rural area.

Cyber-bullying: Mukherjee (2021) reported that cases of cyber-bullying, misbehaviour, sexual harassment and abuse has increased in huge numbers during online teaching. Any online meeting or online lectures could be hacked easily and disturbance could be created. For example, in Kolkata, a prominent school ditched online classes after hackers sneaked into several lectures and displayed obscene videos on the screen and threatened the students and teachers. As a result, teachers had to suspend the online classes. This happens normally in rural area especially with female teachers in India. In Malaysia, cyber-bullying happens, and research shows that children who like to bully in traditional classes are prompt to involve in the cyber-bullying.

Mischief by Students: Reports of irrelevant messages in the chat box of google meet by a few students during the lockdown were found. This creates confusion and stress for the teachers as well as other students. There is no control on the audience behaviour. The result of mischief by students' prompt physical and mental stress felt by teachers and other students in class in both India and Malaysia.

Isolation: Teacher feels isolated as lecture is conducted through online mode. Teachers are not able to see the reaction of the students as most of the time they keep their video off while teaching is going on. In addition, teachers are not able to meet their colleagues. Social contact ends in online mode of teaching (Zembylas et al., 2008; Arkorful \& Abaidoo, 2015). This implies to both the country.

Lack of self-efficacy: Online teaching practices does not help to understand the children's need which may lead to ineffective classroom teaching. Lack of teacher's knowledge about practical applicability of online classroom teaching leads to great obstacles. Pierce-Friedman (2018) shows that greater feelings of working in isolation predicted decreased feelings of lower self-efficacy for the online teacher in both countries.

Procrastinate: Online classes make it easier to procrastinate the schedules if not followed properly. This is basically seen due to loss or poor network connectivity which hinders the work of the teacher. Its seen that students and the teachers are not punctual in time, sessions do continue for longer period of time than assigned. As a result, the time is wasted, students lose the interests in learning and concept remains vague. This applies to both countries. 
Oversaturation with information: In many instances, the amount of information, help and resources provided online can tend to become overwhelming and confusing if not properly managed. It can be difficult for students and teachers to discern which are relevant or important. The teachers send a large amount of information without providing specific instructions. Supplementary materials are too much which lead to chaos in both countries.

Less exposure to practical: Practical is not possible in online teaching, and even effective control related to assignment proves to be difficult. Limited exposure to field, practical, or actual practice results in low achievement of the students, including both technical and social science studies. This hold true for both the countries.

Lack of focus and attention: While teaching online, attention on each and every student is difficult. One of the reasons for this incident may include ignorance in the use of technology among students and teachers. After handling this issue, when the teacher is coming back on topic, it distracts the focus of the teacher as the online mode was new to them. This was the case for most of the senior teachers in both the countries.

Lack of control and monitoring: It becomes difficulty on the part of the teacher to check what the students are doing while the teaching is going on. Basically, its seen that students turn off their camera and sit, so to check actual effective teaching and learning it becomes difficult to know. This implies to both of the countries.

Poor holistic approach: It seems that online teaching hardly promotes the values such as discipline, teamwork, leadership, motivation, competition, and comparison which is essential for education in both the countries.

Network issues: In many places especially in the rural areas, the number of mobile towers are very less which results in loss of internet connectivity and disruption in online classes. Poor call quality, technology issues, network issues, power issues affect the online classes badly, which holds true for both countries as suggested by students, teachers, and parents.

Economy: For population residing in rural areas or having very low income, getting access to mobile data is quite difficult. And without data, there is no online education. Many remote places don't even have electricity lines to their homes and even in urban areas too, electricity fluctuates. Since people cannot charge their devices, they can't get proper education via the online mode in India. For people with low family income affording a decent smart phone is unachievable. It can also be the case that there is only one smartphone amongst all the members of a family which turn it nearly impossible to get online education (Mukherjee, 2021). This implies to the lower- and middle-income group members of both countries.

Home environment: If the home infrastructure and environment is not conducive, then it's a big hindrance to online teaching. It may lead to lack of communication and concentration. Darji (2020) states that home environment is affecting the teachers and learner's online teaching-learning in India. While in Malaysia, the home environment is focused, and most families have at least a study area or a room for the study purpose. 
Classroom environment: Students often miss learning collectively with other students inside a classroom. Physical interaction between teachers and students and amongst the students themselves adds a different dimension to the learning experience which was represented by the prospects of both countries.

Attention span: Research suggests that one can keep total concentration while learning for a very limited amount of time and if teacher doesn't have all the audio-visual tools at their disposal, then online learning becomes very boring for the students and makes them loose concentration on what is being taught. Students tend to lose the attention during online teaching, in both the counties.

Health Issues: Reports have shown that students, parents have complained of pain on eyes, stress, headaches. According to article report, psychiatrist said that prolonged exposure to online classes may result into isolation, anxiety, depression which is compared with words cannabis addiction. Other problems like muscle stiffness, cramp, deficiencies of calcium and vitamin D, lack of physical activities is seen among students and teachers as well in both countries.

Assessment: The reliable assessment is nearly difficult in the online education. Educator's lack of knowledge about how to evaluate the learners' knowledge and skills in online learning environment" (Darji, 2020). This implies in both the countries, India and Malaysia.

Failure to cater the students: Online teaching is mostly the model of 'one size fits all' that ignores the needs of students. It fails to cater the individual interests and abilities of the students, teaching skills, and student motivation during online teaching in both countries.

As per the finding form the students, teachers, and the parents, online teaching faces numerous challenges, where it need serious attention from the system. As early do we focus to solve the challenges, better will be the result. No doubt, that the traditional teaching cannot be replace with any other mode of teaching, but it is equally true that we cannot undermine and neglect the power of online teaching. Maybe online teaching cannot be an alternative to the traditional teaching, but it can be the best supplement for the education system now and in the future.

\section{Recommendation and Conclusion}

Currently, the pandemic is sparking a global discussion about how knowledge, education, and learning need to be reimagined in a world that is becoming increasingly complex, uncertain, and precarious. There are numerous merits and challenges raised in this study that are relevant in the current pandemic as well as in the future. We summarise the issues raised and make recommendations for future development based on their merits in the following sections, in the hope that they will facilitate discussions among researchers and practitioners on how to rethink education and shape the future of online teaching in the future.

i. Initiate motivation- Attending to the initial and ongoing motivation of students and teachers in preparation for an emergency transition from face-to-face to online (remote) learning is essential. This requires a thorough understanding of the 
DEVELOPMENT

Vol. 10, No. 2, 2021, E-ISSN: 2226-6348 @ 2021 HRMARS

motivational process, from the initial arousal of desire to the sustained motivation in unfamiliar and unexpected environments.

ii. Readiness of the society towards online teaching-Teachers, students and parents need to be acknowledged with technology advancement and its application in education. This may help to deliver better teaching materials, develop online teaching and have better communication apart of adding to the knowledge.

iii. Prepare student for future learning-Most of the current research suggests that selfdirected and collaborative learning are prerequisite skills for online instruction. This includes nurturing skills and cultivating self-efficacy from a variety of perspectives of online teaching.

iv. Gender equalities- Program should be designed to develop gender equalities among the students and even teachers. Peer groups, team teaching and projects could be given to the students and teachers irrespective of their gender.

v. Promote collaboration- Peer-to-peer support through technology must be promoted to enable social and collaborative environments and emphasis should be laid on the importance of collaborative learning, specifically mutual peer support and social presence.

vi. Assist minority groups- Efforts should be placed to assist minority groups, such as students with students who live in rural areas, and students with special education needs in their educational endeavours.

vii. Conduct research-Significant research should be conducted to know pandemic effects on educational policies in Asian countries, comparing them to policies in more progressive countries in order to better rethink what our future digital education should look like.

\section{MERITS, CHALLENGES AND RECOMMENDATIONS OF ONLINE TEACHING}

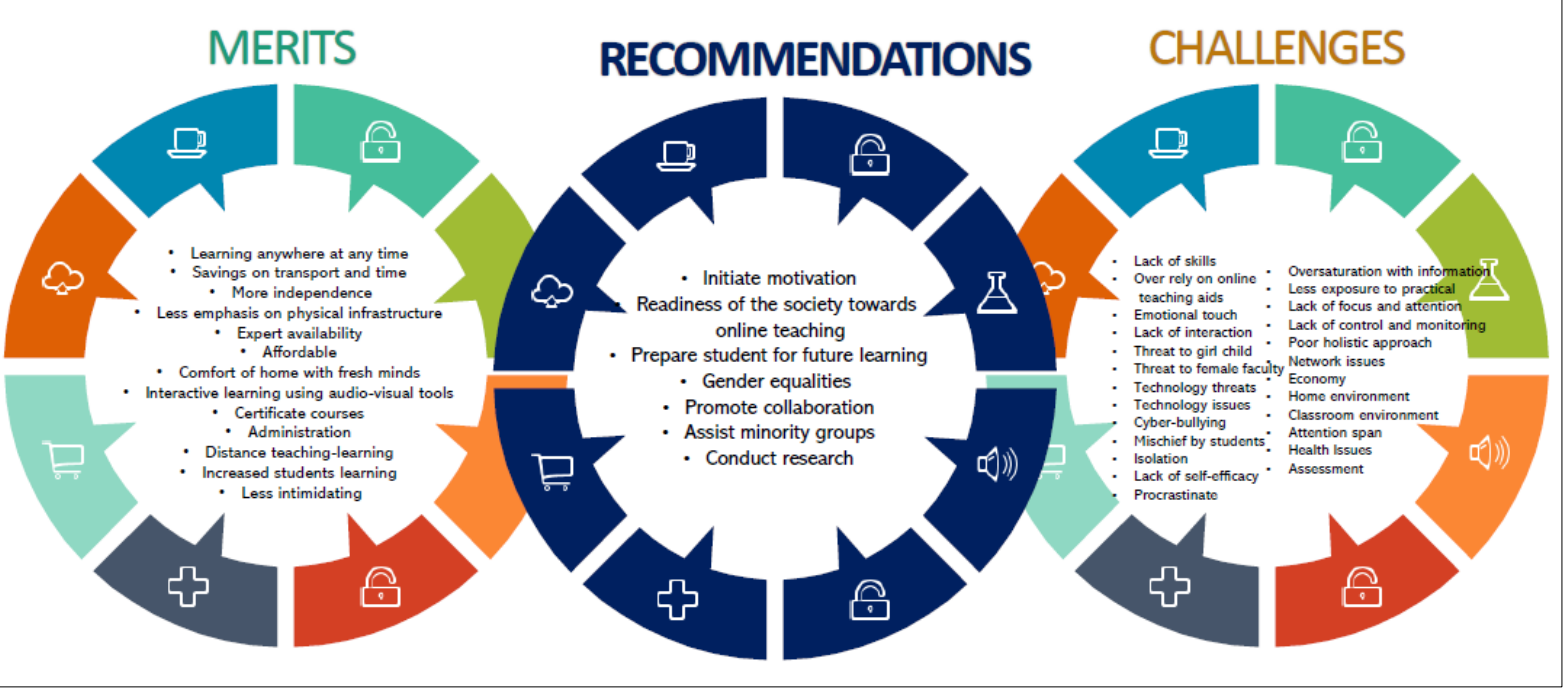

Figure 1: Merit, Challenges, and Recommendations of Online Teaching

Online teaching has both the dark and positive sides for both the countries which are nearly similar (Figure 1). The findings indicate that major merits of online teaching include flexibility in learning, economical with respect to time, money, and energy, access to knowledge, and 
fostering communication. The major challenges are issues and threat of technology, gender issues, and problems associated with rural people. Whereas the merits depict the ease and comfort of online teaching, the technological issues and its threats present its challenges. Maybe, in the present time, the challenges may seem will more challenging and posits many difficulties, but the fact remains that all the challenges of the online teaching can be addressed positively. Whereas the study concludes the similarity and differences of the merits and challenges of online teaching among two countries and provides a new insight to the future academicians and practitioners as presented in Figure 1, it demands rigorous research for online teaching for further clarity.

The study contributes to the clarity of the ideas about the merits and challenges of online teaching. Nevertheless, it entails and ascertains the advantages and disadvantages as the merits and the challenges of online teaching. Whereas the online teaching serves as a boon in this time of pandemic simultaneously it also brings about with its application the lot many challenges which needs to be addressed without any delay. Today in this time of pandemic when the world is marked by increasing ill-structuredness, unpredictability, complexity, and novelty, education cannot remain an exception. With inclusion of online teaching in education, the ill-structuredness, unpredictability, complexity, and novelty has added to the merits and challenges of online teaching which is highlighted in the study. The same may serve as a basis for the students, teachers and parents to contribute to the education and teaching learning process. Each of the challenges depicted in the study are the cases of ill-structured domains of the online teaching that demands instructional guidelines for advancement of the potential prospects which is in concordance with the cognitive flexibility theory that propagates to prepare students to deal to manage real-world complexity and to deal adaptively with novel, ill-defined problems. Although the study contributes to the lucidity with respect to the online teaching however, this study demands further researches to assess and ensure these merits and challenges as the factors affecting the online teaching etc. The experiential survey of the same may add to the precision as well serve to find its possible solutions especially with respect to the challenges of online teaching which in turn may turn as a future research study.

\section{References}

Arkorful, V., \& Abaidoo, N. (2015). The role of e-learning, advantages and disadvantages of its adoption in higher education. International Journal of Instructional Technology and Distance Learning, 12(1), 29-42.

Botham, R., \& Mason, C. (2007). Good Practice in Enterprise Development in UK Higher Education. Birmingham: National Council for Graduate Entrepreneurship. Birmingham.

Cheng, J., \& Koszalka, T. (2016). Cognitive flexibility theory and its application to learning resources. Retrieved from http://ridlr.syr.edu/publications/

Darji, C. (2020). Status of online and face to face teaching: A survey, Tathapi (UGC Care Journal), 19, 43.

Huang, J. (2020). Successes and Challenges: Online Teaching and Learning of Chemistry in Higher Education in China in the Time of COVID-19. Journal of Chemical Education, 97(9), 2810-2814.

Kim, K., \& Bonk, C. J. (2006). The future of online teaching and learning in higher education: The survey says. Educause Quarterly, 29(4), 22. 
Li, C., \& Lalani. F. (2020, April 29). The COVID-19 pandemic has changed education forever. This is how. World Economic Forum. https://www.weforum.org/agenda/2020/04/coronaviruseducation-global-covid19online-digital-learning/

Mathew, I. R., \& Ebelelloanya, J. (2016). Open and distance learning: Benefits and challenges of technology usage for online teaching and learning in Africa.

Mukherjee, A. (2021). Implications of Online Education in COVID: 19 Pandemic: A Review. NSOU: OPEN JOURNAI, Vol.4 No.1

Muthuprasad, T., Aiswarya, S., Aditya, K. S., \& Jha, G. K. (2021). Students' perception and preference for online education in India during COVID-19 pandemic. Social Sciences \& Humanities Open, 3(1), 100101.

Paudel, P. (2021). Online education: Benefits, challenges and strategies during and after COVID-19 in higher education. International Journal on Studies in Education, 3(2), 70-85.

Pierce, P. F. (2018). Self: efficacy and Isolation: Teaching Online. International Journal for Cross: Disciplinary Subjects in Education (IJCDSE). 9, 1.

Simamora, R. M. (2020). The Challenges of online learning during the COVID-19 pandemic: An essay analysis of performing arts education students. Studies in Learning and Teaching, 1(2), 86-103.

Sun, A., \& Chen, X. (2016). Online education and its effective practice: A research review. Journal of Information Technology Education: Research, 15, 157: 190.

Spiro, R. J., Coulson, R. L., Feltovich, P. J., \& Anderson, D. K. (1988). Cognitive flexibility theory: Advanced knowledge acquisition in ill-structured domains. Tenth annual conference of the Cognitive Science Society (pp.375-383). Hillsdale, NJ: Erlbaum.

Spiro, R. J., Feltovich, P. J., Jacobson, M. J., \& Coulson, R. L. (1992). Cognitive flexibility, constructivism, and hypertext: Random access instruction for advanced knowledge acquisition in ill-structured domains. In T. M. Duffy \& D. H. Jonassen (Eds.), Constructivism and the technology of instruction: A conversation (pp.57-76). Hillsdale, NJ: Lawerence Erlbaum Associates.

Spiro, R. J., \& Jehng, J. C. (1990). Cognitive flexibility, random access instruction, and hypertext: Theoryand technology for the nonlinear and multidimensional traversal of complex subject matter. In D. Nix and R. J. Spiro (Eds.), Cognition, education, and multimedia (pp.163-205). Hillsdale, NJ: Erlbaum.

Spiro, R. J., Klautke, H. A., Cheng, C., \& Gaunt, A. (2017). Cognitive fexibility theory and the assessment of 21st-century skills. In C. Secolsky \& D. B. Denison (Eds.), Handbook on measurement, assessment, and evaluation in higher education (pp. 631-637). NY: Routledge

West, D. M. (2012). Digital Schools: How technology can transform education. Washington:DC: Brookings Institution Press.

Yusuf, B. N., \& Jihan, A. (2020). Are we prepared enough? A case study of challenges in online learning in a private higher learning institution during the Covid-19 outbreaks. Advances in Social Sciences Research Journal, 7(5), 205-212. 